\title{
Emergency obstretic hysterectomy: a retrospective study in a tertiary care center
}

\author{
Vaishnavi Sanjay Shivade*, Vaishali S. Vhawal, Manisha M. Laddad
}

Department of Obstetrics and Gynecology, Krishna Institute of Medical Sciences, Karad, Maharashtra, India

Received: 29 March 2019

Accepted: 06 May 2019

\section{*Correspondence:}

Dr. Vaishnavi Sanjay Shivade,

E-mail: vaishnavishivade@gmail.com

Copyright: () the author(s), publisher and licensee Medip Academy. This is an open-access article distributed under the terms of the Creative Commons Attribution Non-Commercial License, which permits unrestricted non-commercial use, distribution, and reproduction in any medium, provided the original work is properly cited.

\begin{abstract}
Background: Obstetric hysterectomy remains a necessity in preventing maternal mortality in catastrophic rupture of the uterus or intractable postpartum hemorrhage when all the conservative management options fail. Uterine atony followed by abnormal placentation remains the primary indication of emergency obstratic hysterectomy worldwide. In majority of cases, anticipation, prompt resuscitation and earlier surgical intervention by skilled operator will reduce patient's morbidity and mortality. The first successful operation was performed in 1876. The main objective of the study was to study frequency, indications and fetomaternal outcome of emergency obstetric hysterectomy in tertiary care center.

Methods: Observational, retrospective and analytical study was done over 2 years from January 2017 to January 2019. A total of 11 cases of emergency obstretic hysterectomy (EOH) were recorded.

Results: The overall incidence was 1.47 per 1000 deliveries. Atonic postpartum hemorrhage (54\%) was the most common indication followed by placenta previa (18\%) and placenta accreta (9\%). Second gravida were mostly involved (45\%) with previous LSCS (45\%) as a common risk factor in commonest age group of 20-25 years (46\%) amongst them. The most frequent squeal was disseminated intravascular coagulation (45\%). Maternal mortality was nil while neonatal mortality being $9 \%$. The decision of performing total or subtotal hysterectomy along with bilateral internal iliac ligation was influenced by patient's condition.

Conclusions: Emergency obstretic hysterectomy is the most demanding obstretic surgery performed in circumstances of life threatening hemorrhages where conservative surgical modalities fail and interventional radiology is not immediately available. Antenatal anticipation of the risk factors, involvement of experienced obstetrician at the early stage of management and prompt hystrectomy after adequate rescuitation will reduce fetomaternal mortality and morbidity.
\end{abstract}

Keywords: Atonic postpartum hemorrhage, Emergency obstetric hysterectomy, Placenta accreta

\section{INTRODUCTION}

Emergency obstetric hysterectomy (EOH) is defined as extirpation of the uterus either at the time of cesarean section or following vaginal delivery, or within the puerperium period. A near miss event is defined as a woman who nearly died but survived a complication that occurred during pregnancy, childbirth, or within 42 days of termination of pregnancy. ${ }^{1} \mathrm{EOH}$ can be rightly classified as a near miss event.

Conservative methods such as community-based use of misoprostol, oxytocin in the prefilled auto-disable drug delivery systems, condom catheter balloon, and non- 
inflatable anti-shock garments for the management of hypovolemic shock have all been advocated to effectively manage obstetric hemorrhage in low resource settings. ${ }^{2}$ Advances in interventional radiology have also provided the option of uterine artery embolization.,

EPH is the most dramatic operation in modern obstetrics and is generally performed when all conservative measures have failed to achieve haemostasis in the setting of life threatening hemorrhage. The unplanned nature of the surgery and the need for performing it expeditiously, compound matters. Moreover the acute loss of blood renders the patient in a less than ideal condition to undergo emergency surgical intervention. The predominant indications for $\mathrm{EOH}$ are uterine atony, placenta previa/accreta and EOH in some of them is unavoidable. ${ }^{5}$ However recognizing and assessing patients at risk and appropriate and timely intervention would go a long way in ensuring a better outcome in this otherwise difficult situation.

\section{METHODS}

This was a retrospective, observational, analytical study of parturient women requiring EOH/emergency obstretic hysterectomy. We looked at data over two years period, from January 2017 to January 2019 from the Department of Obstetrics and Gynecology, Krishna Institute of Medical Sciences, Karad, India.

EPH was defined as hysterectomy performed for hemorrhage unresponsive to other therapeutic interventions, at the time of cesarean section or vaginal delivery, or within puerperium. ${ }^{5}$ Inclusion criteria included all women who delivered in the hospital between January 2017 to January 2019 and who underwent hysterectomy for obstetric indications at the time of delivery irrespective of the gestational age or subsequently within the defined period of puerperium (42 days). All women who delivered outside the hospital and were referred for obstetric complications meriting a hysterectomy and fulfilling all the above conditions were also included in the study.

After collecting relevant data from the operation theatre records, each patient's case record was scrutinized with regard to incidence, age, parity, antenatal high risk factors, indications, hysterectomy type, and complications, along with the ultimate feto-maternal outcome. Institutional ethical committee approval was obtained for the study.

\section{RESULTS}

Out of 7449 deliveries, total 11 obstretic hysterectomies were performed over 2 years, the incidence of the study was $0.0014 \%$ ( 1.47 hysterectomies per 1000 deliveries) out of which all the EOH followed cesarean section 2.99 hysterectomies per 1000 cesarean section, and nil followed vaginal delivery (Table 1 ).

Table 1: Association of cesarean section and normal deliveries with EOH.

\begin{tabular}{|llll|}
\hline & $\begin{array}{l}\text { Number of } \\
\text { patients }\end{array}$ & EOH & Incidence \\
\hline $\begin{array}{l}\text { Normal vaginal } \\
\text { deliveries }\end{array}$ & 4108 & 0 & $0 \%$ \\
\hline Cesarean section & 3341 & 10 & $0.29 \%$ \\
\hline MTP & 353 & 1 & $0.283 \%$ \\
\hline Total & 7802 & 11 & \\
\hline
\end{tabular}

Table 2: Age and parity distribution of women included in the study.

\begin{tabular}{|c|c|c|c|c|c|c|}
\hline Age(years) & Parity P1 & P2 & P3 & P4 & $>$ P5 & Total \\
\hline$<20$ & 1 & 0 & 0 & 0 & 0 & 1 \\
\hline $20-25$ & 0 & 4 & 0 & 0 & 0 & 4 \\
\hline $25-30$ & 1 & 0 & 1 & 0 & 0 & 2 \\
\hline $30-35$ & 0 & 0 & 1 & 2 & 0 & 3 \\
\hline$>35$ & 0 & 0 & 0 & 0 & 1 & 1 \\
\hline Total & 1 & 4 & 2 & 2 & 1 & 11 \\
\hline
\end{tabular}

While second gravida aging between $20-25$ years (Table 2) had $36 \%$ incidence of undergoing EPH. Atonic postpartum hemorrhage was found to be the commonest indication for EPH in the study with invidence of $54 \%$ (Table 3). This would include primary postpartum hemorrhage with blood loss of more than 2 litres in approximately all the cases. Retained placental tissue and infection was ruled out. No cases of secondary PPH were observed. Intraoperative findings were flabby uterus inspite of adequate uterine massage and uterotonics, tachycardia, hypotension and tachypnoea. Common associated factor amongst them was previous lscs scar, incidence being $27 \%$ (Table 4). In postoperative period, $45 \%$ of the patient suffered from disseminated intravascular coagulopathy requiring close monitoring of vitals, transfusion of blood products and intensive care unit stay (Table 5). Optimal days required for recovery of the patient was observed to be around 6 to 7 days. Incidence of maternal death amongst these cases was found to be nil (Table 5) while neonatal mortality obseved was $9 \%$ (Table 5).

Also, out of 353 MTPs conducted in the hospital,only one case underwent postprocedure intractable hemorrhage for 
which EPH needed to be done,thus incidence of EPH amongst MTPs being $0.283 \%$ over 2 years (Table 1 ).

Table 3: Indications of emergency obstetric hysterectomy in the study population.

\begin{tabular}{|lll|}
\hline Indications & Number & Percentage \\
\hline Atonic PPH & 6 & 54 \\
\hline Placenta previa & 2 & 18 \\
\hline Adherent placenta & 1 & 9 \\
\hline Abruptio placenta & 1 & 9 \\
\hline Uterine rupture & 0 & 0 \\
\hline Post MTP & 1 & 9 \\
\hline Total & 11 & 100 \\
\hline
\end{tabular}

Table 4: Other associated risk factors.

\begin{tabular}{|lll|}
\hline Risk factor & Number & Percentage \\
\hline Preeclampsia & 2 & 18 \\
\hline Previous lscs & 3 & 27 \\
\hline Fetal macrosomia & 1 & 9 \\
\hline Anemia & 2 & 18 \\
\hline $\begin{array}{l}\text { Others (PROM, } \\
\begin{array}{l}\text { Oligohydrominos, twins, } \\
\text { prolonged labor, fibroid) }\end{array}\end{array}$ & 2 & 18 \\
\hline
\end{tabular}

Table 5: Feto-maternal complications.

\begin{tabular}{|lll|}
\hline Complications & Number & Percentage \\
\hline Coagulopathy (DIC) & 5 & 45 \\
\hline Need of vasopressors & 4 & 36 \\
\hline ICU stay & 5 & 45 \\
\hline Fever & 0 & 0 \\
\hline Wound sepsis & 0 & 0 \\
\hline Relaparotomy & 1 & 9 \\
\hline Maternal mortality & 0 & 0 \\
\hline $\begin{array}{l}\text { Others (PSY trauma, } \\
\text { vesicovaginal fistula, } \\
\text { bladder injury, neurodeficit) }\end{array}$ & 0 & 0 \\
\hline NICU admission & 1 & 9 \\
\hline Neonatal mortality & 1 & 9 \\
\hline
\end{tabular}

\section{DISCUSSION}

Storer performed the first cesarean hysterectomy in the United States in 1869. Soon thereafter, Porro of Milan described the first cesarean hysterectomy in which the infant and mother survived. ${ }^{6}$ As a mark of honor, the procedure is frequently referred to as the Porro operation. $^{7}$

The decreasing rate of abdominal hysterectomy for gynecological conditions in recent years does not help matters with regard to gaining this valuable experience. ${ }^{8}$ This implies that more effort should be undertaken to recognize the potential risk of patients requiring EPH and the need for involvement of an experienced obstetrician in the management at an early stage. EPH being performed by an experienced surgeon is reported to significantly reduce the operating time, number of units of blood transfusion and hospital stay. The predisposing risk factors can be determined to a certain extent by performing antenatal ultrasound with color Doppler and magnetic resonance imaging (MRI). Persistent blood flow after the latent phase is suspicious of placenta accreta. However, the limiting factor is the high cost of MRI and extensive experience needed.

Conservative measures to arrest bleeding are initially tried before considering EOH. ${ }^{9-12}$ The measures include uterotonic drugs, uterine or hypogastric artery embolisation, hemostatic sutures, uterine or internal iliac artery ligation. Conservative management is of particular importance in patients who are young, have low parity and who are haemodynamically stable. However while there are reports of $96 \%$ success rate following uterine artery ligation. ${ }^{11}$ There are others who have achieved success in only $39.4 \%$ of these cases. The choice between conservative management and EOH should be individualized. In situations where conservative treatment is likely to fail or has failed, there should be no further delay in performing $\mathrm{EOH}$ as delay leads to increase in blood loss, transfusion requirement, operative time, DIC, and increased possibility of admission to ICU.

Multiparity and oxytocin use for uterine stimulation were found to be the risk factors for uterine atony requiring $\mathrm{EOH}$. Combs et al in their large case control study of patients with post partum hemorrhage reported that preeclampsia, nulliparity, twins, induction, prolonged labor and augmentation were all identified as independent risk factors for uterine atony. ${ }^{13}$

Total hysterectomy is the recommended surgical method of $\mathrm{EOH}$ due to the potential risk of malignancy developing in the cervical stump and the need for regular cytology and other associated problems such as bleeding or discharge associated with the residual cervical stump. ${ }^{14,15}$ Currently the proportion of subtotal hysterectomy performed for $\mathrm{EOH}$ ranges from $53 \%$ to $80 \% .^{16,17}$ The proponents of subtotal hysterectomy report a lesser blood loss, a reduced need for blood transfusion, reduced operating time and reduced intra and postoperative complications. Subtotal hysterectomy may not be effective in management of accreta located in lower uterus. Total hysterectomy should however be considered when active bleeding occurs from lower uterine segment as the cervical branch of uterine artery may remain intact. Both total and subtotal hysterectomy are however associated with high mortality. ${ }^{18-20}$ All pedicles are doubly ligated because of hyperemia and peripartum pelvic tissue tears. The final decision to perform subtotal or total hysterectomy would be influenced by patient's condition. Hence, while total abdominal hysterectomy is a more convenient procedure, subtotal EPH may be a better choice in certain conditions where surgery needs to be completed in a shorter time. 


\section{CONCLUSION}

Although no risk assessment system can predict all instances where cesarean delivery will be needed, a significant percentage of the patients who are at high risk for severe hemorrhage and the subsequent need of emergency hysterectomy can be identified before surgery. The preoperative risk factors include previous history of CS, placenta previa and accreta. The presence of preoperative risk factors should facilitate consultation, referral or transfer of patients before surgery to a tertiary care facility. Due to the complexity of the surgery and decision making, the involvement of an experienced obstetrician at an early stage is desirable. Proper surgical measures such as hemostatic sutures or uterine or hypogastric artery ligation or embolization are options in attempting uterine conservation particularly in patients who are young and in whom future fertility is important and who are relatively haemodynamically stable. When conservative treatment is not feasible or has failed, prompt EPH is performed failing which the delay would contribute to the maternal morbidity and in unfortunate cases mortality.

\section{Funding: No funding sources}

Conflict of interest: None declared

Ethical approval: The study was approved by the Institutional Ethics Committee

\section{REFERENCES}

1. Say L, Souza JP, Pattinson RC, WHO working group on Maternal Mortality and Morbidity classifications. Maternal near miss towards a standard tool for monitoring quality of maternal health care. Best Pract Res Clin Obstet Gynaecol. 2009;23(3):287-96.

2. Miller S, Lester F, Hensleigh P. Prevention and treatment of postpartum hemorrhage: new advances for low-resource settings. J Midwifery Womens Health. 2004;49(4):283-92.

3. Singhal S, Singh A, Raghunandan C, Gupta U, Dutt S. Uterine artery embolization: exploring new dimensions in obstetric emergencies. Oman Med J. 2014;29(3):217-9.

4. Varghese S, Gokulam N. Al- Abri S. Uterine artery embolization in postpartum hemorrhage: a case report. Oman Med J. 2012;27(2).10.5001/omj. 2012.41.

5. Say L, Chou D, Gemmill A, Tunçalp Ö, Moller AB, Daniels J, et al. Global causes of maternal death: a WHO systematic analysis. Lancet Glob Health. 2014;2(6):e323-e333.

6. Cameron CA, Roberts CL, Olive EC, Ford JB, Fischer WE. Trends in postpartum haemorrhage. Aust N Z J Public Health. 2006;30(2):151-6.
7. Durfee RB. Evolution of cesarean hysterectomy. Clin Obstet Gynecol 1969;12(3):575-89.

8. Tunçalp O, Hindin MJ, Souza JP, Chou D, Say L. The prevalence of maternal near miss: a systematic review. BJOG. 2012;119(6):653-61.

9. El Jallad MF, Zayed F, Al-Rimawi HS. Emergency peripartum hysterectomy in Northern Jordon: indications and obstetric outcome (an 8 year review) Arch Gynecol Obstet. 2004;270(4):271-3.

10. Zamzami TY. Indications of emergency peripartum hysterectomy: review of 17 cases. Arch Gynecol Obstet. 2003;268(3):131-5.

11. O'Leary JA. Uterine artery ligation in the control of postcesarean haemorrhage. J Reprod Med. 1995;40(3):189-93.

12. B-Lynch C, Coker A, Loval AH. The B-Lynch surgical technique for control of massive post partum haemorrhage: an alternative to hysterectomy? Five Cases Reported. $\mathrm{Br}$ J Obstet Gynecol. 1997;104(3):372-5.

13. Say L, Chou D, Gemmill A, Tunçalp Ö, Moller AB, Daniels J, et al. Global causes of maternal death: a WHO systematic analysis. Lancet Glob Health. 2014;2(6):e323-e333.

14. Greer I, Lang G, Patel N. The management of postpartum haemorrhage. aberdeen: scottish obstetric guidelines and audit project. 1998.

15. Roopnarinesingh R, Fay L, McKenna P. A 27-year review of obstetric hysterectomy. J Obstet Gynaecol 2003;23(3):252-4.

16. Christopoulos P, Hassiakos D, Tsitoura A, Panoulis K, Papadias K, Vitoratos N. Obstetric hysterectomy. A review of cases over 16 years. J Obstet Gynecol. 2011;31(2):139-41.

17. Stanco LM, Schrimmer DB, Paul RH, Mishell DR. Emergency peripartum hysterectomy and associated risk factors. Am J Obstet Gynecol. 1993;168(3):87983.

18. Engelsen IB, Albrechtsen S, Iversen OE. Peripartum hysterectomy - incidence and maternal morbidity. Acta Obstet Gynecol Scand. 2001;80(5):409-12.

19. Stanco LM, Schrimmer DB, Paul RH, Mishell DR. Emergency peripartum hysterectomy and associated risk factors. Am J Obstet Gynecol. 1993;168(3):87983.

20. Chanrachakul B, Chaturachinda K, Phuspradit W, Roungsipragarn R. Cesarean and post partum hysterectomy. Int J Gynecol Obstet. 1996;54(2):10913.

Cite this article as: Shivade VS, Vhawal VS,

Laddad MM. Emergency obstretic hysterectomy: a retrospective study in a tertiary care center. Int J Reprod Contracept Obstet Gynecol 2019;8:2368-71. 